\title{
Comprehensive assessment of older people with complex care needs: the multi-disciplinarity of the Single Assessment Process in England
}

\author{
DAVID CHALLIS*, MICHELE ABENDSTERN*, \\ PAUL CLARKSON*, JANE HUGHES* \\ and CAROLINE SUTCLIFFE*
}

\begin{abstract}
The quality of assessment of older people with health and social care needs has for some time been a concern of policy makers, practitioners, older people and carers in the United Kingdom and internationally. This article seeks to address a key aspect of these concerns, namely whether sufficient expertise is deployed when, as a basis for a care plan and service allocation, an older person's eligibility for local authority adult social-care services requires a comprehensive needs assessment of their usually complex and multiple problems. Is an adequate range of professionals engaged, and is a multi-disciplinary approach applied? The Single Assessment Process (SAP) was introduced in England in 2004 to promote a multidisciplinary model of service delivery. After its introduction, a survey in 2005-06 was conducted to establish the prevalence and patterns of comprehensive assessment practice across England. The reported arrangements for multidisciplinary working among local authority areas in England were categorised and reviewed. The findings suggest, first, that the provision of comprehensive assessments of older people that require the expertise of multiple professionals is limited, except where the possibility arose of placement in a care-home-withnursing, and second that by and large a systematic multi-disciplinary approach was absent. Policy initiatives to address the difficulties in assessment need to be more prescriptive if they are to produce the intended outcomes.
\end{abstract}

KEY WORDS - comprehensive assessment, multi-disciplinary assessment, older people, Single Assessment Process, local authority adult services.

\section{Introduction}

The quality of assessment of older people with health and social care needs has for some time been a concern of policy makers, practitioners, service

* Personal Social Services Research Unit, University of Manchester, Manchester, UK. 
users and carers in the United Kingdom (UK) and internationally (Carpenter 1998; Challis et al. 2004; Byles 2000; Howe and Kung 2003; Ikegami 1997; Jorg et al. 2002; Kane and Kane 2000; Otis and Butler 1997). This article seeks to address a key aspect of these concerns, the assessment of older people with complex needs who are likely to require a comprehensive assessment that requires a range of professional expertise. It is considered in the context of the adoption in England in April 2004 of the Single Assessment Process (SAP), a government initiative to improve the standard of assessment for older people with health and social care needs (Department of Health 2001 $a$, 2002). Similar strategies have been introduced elsewhere, such as the Australian Community Care Needs Assessment (Australia, Department of Health and Ageing 2007).

The concept of comprehensive assessment can be traced back to the pioneers in public health and welfare who noted the importance of seeing the older person 'in the round' (Warren I946), and who recognised that health and social care needs overlap, are often unrecognised, and that co-ordination between professionals is required if individual needs are to be met (Booth i98I; Williamson et al. i964). Internationally, the idea of comprehensive geriatric assessment has been advanced as a way of eliciting the full range of needs of older people (Applegate et al. 1990; Stuck et al. 1993). Despite this history, many UK studies have reported that the assessment of older people is disjointed and compartmentalised (Challis et al. 1995, 2001; Chevannes 2002; Glasby 2003; Gray and Hunter 1983; Hudson et al. 1998; Hunter and Wistow 1987; Petch et al. 1996; Weiner et al. 2002). Some have commented that assessors tend to view the subject in isolation from their social world (Webb and Hobdell i978), and that assessments involve many encounters between individual professionals and older people but poor communication among them (Audit Commission 1997; Department of Health 1993 $a$, I993 $b$, I996; House of Commons Health Select Committee 1998; Social Services Inspectorate 1997).

Few recent reviews of the impact of comprehensive assessment have addressed the impact on those at significant risk who are living at home. Studies have focused upon in-patient groups (Ellis and Langhorne 2005), and preventive visiting (Bouman et al. 2007, 2008), or on assessments in conjunction with specific, complex interventions (Beswick et al. 2008). Stuck and Kane (2008) concluded that although preventive home visits are not beneficial for high-risk individuals, other more targeted and focused interventions may be (Gill et al. 2002; Phelan et al. 2004; Naylor et al. 1999). A randomised controlled trial in England found that a comprehensive assessment process targeted on highly vulnerable older people and undertaken by specialist clinicians and social workers reduced functional 
decline, improved carer wellbeing, and reduced care-home admissions and health-care costs (Challis et al. 2004). This was perhaps the study which perhaps most closely embodies the spirit of the implementation of comprehensive assessment through the SAP.

It was long ago argued that no single professional group has sufficient skills or knowledge to be able to carry out comprehensive assessments alone and that 'teamwork across professional boundaries is needed ... if whole person care is to be possible and the optimal use of skills is to be attained' (Webb and Hobdell $1978:$ 342). The benefits described by Webb and Hobdell of a multi-disciplinary approach to assessment included making the best use of specialist skills and those that derive from the division of labour. Empirical studies have indeed demonstrated a range of benefits of an integrated approach to assessment, including faster and more appropriate responses to requests and reduced provider costs (Challis et al. 2004; Øvretveit 1993). Team work is a key component of effective multi-disciplinary comprehensive assessment. Ovretveit (I993) argued that multi-disciplinary comprehensive assessment can only become systematic when multi-disciplinary teams are led by a single manager. Others have suggested, however, that the key to an effective team is when the power to make decisions is equally shared amongst the professional (and para-professional) members (Sheard and Cox 1998; Webb and Hobdell 1978). In England, the SAP guidance noted that, "where joint teams have been established, the integration of assessment, care planning and service delivery across agencies and disciplines is often reported as less difficult to achieve' (Department of Health 2002: Annex G).

Although there are multi-agency and multi-disciplinary assessment teams in England (Audit Commission 2002; Challis et al. 2002; Hardy, Leedham and Wistow I996), they are not yet mainstream. Studies at the beginning of the millennium indicated that joint assessments, or even consultations with another professional, were not standard practice (Challis et al. 200 ; McNally, Cornes and Clough 2003; Moriarty and Webb 2000; Weiner et al. 2002). Chevannes reported that professionals in health and social care appeared to be 'driven by the specific brief of their agency' and to operate 'outside of an integrated and multidisciplinary assessment process that enables health and social needs to be considered together' (2002: 177). The development of the intermediate care sector, including arrangements to prevent unnecessary hospital admissions and facilitate the rehabilitation of older people following hospital discharge, might change this picture. Such services are typically provided by multi-disciplinary teams in diverse locations, including the patients' homes, care homes and community hospitals (Cowpe 2005; Department of Health 200I $b$; Steiner 200I). 
In Australia, by contrast, 'geriatric assessment teams' were established following the Nursing Homes and Hostels Review of I986 (Australia, Department of Community Services I986), and they formalised multi-disciplinary assessment practice in primary and secondary health care and social care (Challis et al. 1995; Kendig et al. 1992). The Australian experience demonstrates how structural reform at a national level can lead to the integration of assessment at the professional level. On the other hand, the findings of a study that compared old-age psychiatry departments in England and Northern Ireland suggested that professional integration is not an automatic consequence of structural integration (Reilly et al. 2003). Although there was greater 'structural integration' in Northern Ireland, where health and social care are managed by a single body, only limited practicelevel integration was found. In sum, although there are challenges in implementing an effective multi-disciplinary approach to the assessment of older people with complex needs, the pursuit of such an approach has been widely seen as a way of improving the assessment of older people.

\section{The Single Assessment Process}

In England, the difficulty of co-ordinating assessments across professional groups has been exacerbated by the long-established organisational divide between health and social care (Lewis 200I; Webb and Wistow 1986). A number of government policies have sought to mitigate this difficulty by, for example, removing structural barriers to integrated budgets and by creating jointly-managed services (Cameron and Lart 2003; Cm 48I8-I 2000; Cm 6737 2006; Department of Health 2001 $a$, 2002; Rummery and Glendinning 2000). Introduction of the SAP was a formal response to the enduring shortcomings of the assessment process, and sought to provide a structure in which multi-disciplinary assessment would flourish. The national implementation introduced shared tools, assessment procedures and a guidance framework, rather than prescribing a specific intervention. Its overall aims were to establish a standardised assessment process, to raise the standards of assessment, and to ensure that older people's needs are assessed 'in the round' (Department of Health 2001 $a$ : paragraph 2.27).

Four types of assessment are identified in the SAP guidance (contact, overview, specialist and comprehensive), each being triggered by the specific circumstances and needs of an individual (Department of Health 2002). Comprehensive assessment is here defined as an overview together with one or more specialist assessments that are necessary for an older person who is likely to require intensive or prolonged support, which might include permanent admission to a care home, intermediate care (Department of Health 200I $b$ ) or complex care packages at home (Department of 
Health 2002: Annex H). No specific tools were prescribed, although for overview assessments two instruments were used in more than half the localities, namely FACE and Easycare (Clifford 1997; Department of Health 2008; Philp 2000). The official guidance describes the possible range and extent of professional involvement in comprehensive assessments as variable and dependent on the person's individual circumstances, but is more prescriptive in its call for the involvement of particular professionals where placement in a care home or care-home-with-nursing is being considered. In these circumstances the guidance states that:

A comprehensive assessment for people who eventually enter care homes should have involved the input of a range of professionals, with geriatricians, old-age psychiatrists, other consultants working with older people, registered nurses, social workers and therapists playing a prominent role. (Department of Health 2002: Annex H)

Additionally it specifies that where the care home provides nursing care, the co-ordinating or leading role in the assessment process should be played by a registered nurse. The policy therefore seeks to establish more specific arrangements between professionals for certain placement settings. The nature and extent of multi-disciplinary working around assessments of older people consequently provides a key area in which to judge the impact of the policy.

\section{Aims of this paper}

This article seeks to ascertain the degree and nature of comprehensive assessment across England at the beginning of the 2ist century following the introduction of the SAP. It attempts to address whether the comprehensive assessment practice that emerged corresponded to the policy logic that was its instigation (Gostick et al. 1997). Were patterns of multidisciplinary working emerging and, if so, what were they? Did the arrangements conform to the envisaged aims of the policy, to promote a multi-disciplinary approach to this type of assessment across the country? Was the setting in or for which assessment took place important in shaping multi-disciplinary approaches?

\section{Design and methods}

Data were obtained from a national survey of the lead officers responsible for implementation of the SAP policy across the 150 local authority areas in England (Abendstern et al. 2010). A self-completion postal questionnaire was sent to the authorities between October 2005 and May 2006, and there were $122(82 \%)$ completed responses. The local authority was 
therefore the unit of analysis. A sub-set of these data relating to which types of staff participated in a comprehensive assessment are the basis of the analyses reported in this paper. As a framework for the analysis, the specified different purposes of a comprehensive assessment were identified from the policy guidance (Department of Health 2002). These related to four services for which the assessments are undertaken: placement in a care home, placement in a care-home-with-nursing, intensive domiciliary care and intermediate care. Henceforward, for ease of reference, we refer to these as 'sectors' or 'settings' while recognising that they represent the circumstances in which assessments are undertaken rather than the locations of the assessors or the case delivery.

The analysis had two stages. The first involved the construction of variables to identify two indicators of multi-disciplinarity: the professional groups and the number of professions involved. Six recognised professional groups were identified: medical consultants (old-age psychiatrists or geriatricians), general (medical) practitioners, nurses, social workers/care managers, occupational therapists, and housing officers. The number of professions involved in comprehensive assessment were coded into four categories (one, two, three to five, and six or more professionals). These variables were examined for each sector.

The second stage involved multi-dimensional cross-tabulations of the indicators of multi-disciplinarity (professional group and number of professionals) by the sector in which they were undertaken. Cramer's $V$ (sometimes termed Cramer's $C$ ) was used to determine the strength of associations between these indicators; in effect to determine whether the identified patterns of multi-disciplinary working occurred together (Everitt I992; Seigel and Castellan i988). As a rule of thumb, Cramer's $V$ scores of 0.3 or above were taken as 'a fair degree of association between any two variables in a contingency table' (O'Reilly and Rose 1997: 63) and were used as a standard from which to discern whether particular groupings tended to occur together consistently. Using this threshold, we explored the extent to which these associations occurred among the local authorities, the unit of analysis. Only associations found in 5 per cent or more of authorities were included (Challis et al. 200I). We describe the resulting combination of associations as arrangements for the conduct of multidisciplinary assessments within local authorities.

\section{Findings}

Working together: sector and professional group

Table I shows the distribution of the professionals that the local authorities stipulated were required to undertake a comprehensive assessment by 
T A в L E I. Staff contributing to comprehensive assessment, England, 2005-06

\begin{tabular}{|c|c|c|}
\hline Sector and staff group & $\begin{array}{l}\text { Number of } \\
\text { authorities }\end{array}$ & $\%$ \\
\hline \multicolumn{3}{|l|}{ Placement in care home: } \\
\hline Social worker/care manager & 97 & 92 \\
\hline Nurse & 29 & 28 \\
\hline Medical consultant & 23 & 23 \\
\hline General practitioner & II & II \\
\hline Occupational therapist & II & II \\
\hline Housing officer & I & I \\
\hline \multicolumn{3}{|c|}{ Placement in care-home-with-nursing: } \\
\hline Social worker/care manager & 93 & 89 \\
\hline Nurse & 78 & 77 \\
\hline Medical consultant & 40 & 40 \\
\hline General practitioner & I7 & I8 \\
\hline Occupational therapist & II & II \\
\hline Housing officer & I & I \\
\hline \multicolumn{3}{|l|}{ Intermediate care: } \\
\hline Social worker/care manager & 44 & $4^{2}$ \\
\hline Nurse & 40 & 39 \\
\hline Medical consultant & I7 & 17 \\
\hline General practitioner & 9 & 9 \\
\hline Occupational therapist & 26 & 25 \\
\hline Housing officer & I & I \\
\hline \multicolumn{3}{|c|}{ Provision of intensive domiciliary care: } \\
\hline Social worker/care manager & 93 & 89 \\
\hline Nurse & I4 & I4 \\
\hline Medical consultant & 5 & 5 \\
\hline General practitioner & 3 & 3 \\
\hline Occupational therapist & 8 & 8 \\
\hline Housing officer & I & I \\
\hline
\end{tabular}

Notes: Data were available for I07 local authorities. Sample sizes (minimum, maximum): medical consultants (IOI, IO2), general practitioners $(96,99)$, nurses (99, I04), social workers/care managers (I04, I06), occupational therapists (I03, I05), housing officers (99, I00).

sector. It can be seen that, overall, medical consultants, general practitioners, occupational therapists and housing officers were less frequently involved in comprehensive assessments than social workers/care managers. Medical consultants were most frequently involved (in 40 per cent of the authorities) in assessments for placement in a care-home-with-nursing. Occupational therapists were most likely to be involved in assessments for intermediate care $(25 \%)$. Social workers/care managers were involved in the majority of local authorities for placements in care homes or carehomes-with-nursing and for intensive domiciliary care, but less so for intermediate care. Nurses were most frequently involved in assessments for care-homes-with-nursing ( $77 \%)$. A housing officer was involved in comprehensive assessments in only one authority, but in all sectors.

\section{CAMBRIDGE JDURNALS}


T A B L E 2. Professional group by number of personnel contributing to comprehensive assessment, England, 2005-06

\begin{tabular}{|c|c|c|c|c|}
\hline \multirow[b]{2}{*}{ Staff group within sector } & \multicolumn{4}{|c|}{ Number of personnel } \\
\hline & I & 2 & $3^{-5}$ & $6+$ \\
\hline \multicolumn{5}{|l|}{ Placement in care home: } \\
\hline Social worker/care manager & $55(5 \mathrm{I})$ & $22(2 \mathrm{I})$ & I9 (I8) & I (I) \\
\hline Nurse & $\mathrm{o}(\mathrm{o})$ & I3 (I2) & I5 (I4) & I (I) \\
\hline Medical consultant & $\mathrm{o}(\mathrm{o})$ & $5(5)$ & I7 (I6) & I (I) \\
\hline General practitioner & $\mathrm{o}(\mathrm{o})$ & $3(3)$ & $7(7)$ & $\mathrm{I}(\mathrm{I})$ \\
\hline Occupational therapist & $\mathrm{o}(\mathrm{o})$ & $3(3)$ & $7(7)$ & $\mathrm{I}(\mathrm{I})$ \\
\hline Housing officer & $\mathrm{o}(\mathrm{o})$ & $\mathrm{o}(\mathrm{o})$ & $\mathrm{o}(\mathrm{o})$ & $\mathrm{I}(\mathrm{I})$ \\
\hline \multicolumn{5}{|c|}{ Placement in care-home-with-nursing: } \\
\hline Social worker/care manager & I3 (I2) & $39(36)$ & $40(37)$ & I (I) \\
\hline Nurse & $3(3)$ & $3^{8}(36)$ & $36(34)$ & $\mathrm{I}(\mathrm{I})$ \\
\hline Medical consultant & $\mathrm{I}(\mathrm{I})$ & $5(5)$ & $33(3 \mathrm{I})$ & $\mathrm{I}(\mathrm{I})$ \\
\hline General practitioner & $\mathrm{o}(\mathrm{o})$ & $\mathrm{o}(\mathrm{o})$ & I6 (I5) & $\mathrm{I}(\mathrm{I})$ \\
\hline Occupational therapist & $\mathrm{o}(\mathrm{o})$ & $\mathrm{o}(\mathrm{o})$ & Io $(9)$ & $\mathrm{I}(\mathrm{I})$ \\
\hline Housing officer & $\mathrm{o}(\mathrm{o})$ & $\mathrm{o}(\mathrm{o})$ & $\mathrm{o}(\mathrm{o})$ & I $(\mathrm{I})$ \\
\hline \multicolumn{5}{|l|}{ Intermediate care: } \\
\hline Social worker/care manager & $28(26)$ & $7(7)$ & $6(6)$ & $\mathrm{I}(\mathrm{I})$ \\
\hline Nurse & $27(25)$ & $6(6)$ & $6(6)$ & $\mathrm{I}(\mathrm{I})$ \\
\hline Medical consultant & $8(7)$ & $5(5)$ & $2(2)$ & I $(\mathrm{I})$ \\
\hline General practitioner & $3(3)$ & $2(2)$ & $2(2)$ & $\mathrm{I}(\mathrm{I})$ \\
\hline Occupational therapist & I5 (I4) & $3(3)$ & $5(5)$ & $\mathrm{I}(\mathrm{I})$ \\
\hline Housing officer & $\mathrm{o}(\mathrm{o})$ & $\mathrm{o}(\mathrm{o})$ & $\mathrm{o}(\mathrm{o})$ & $\mathrm{I}(\mathrm{I})$ \\
\hline \multicolumn{5}{|c|}{ Provision of intensive domiciliary care: } \\
\hline Social worker/care manager & $34\left(3^{2}\right)$ & I6 (I5) & I8 (I7) & $\mathrm{I}(\mathrm{I})$ \\
\hline Nurse & $\mathrm{o}(\mathrm{o})$ & $3(3)$ & $8(7)$ & I $(\mathrm{I})$ \\
\hline Medical consultant & $\mathrm{I}(\mathrm{I})$ & $\mathrm{o}(\mathrm{o})$ & $3(3)$ & $\mathrm{I}(\mathrm{I})$ \\
\hline General practitioner & $\mathrm{o}(\mathrm{o})$ & $\mathrm{o}(\mathrm{o})$ & $2(2)$ & $\mathrm{I}(\mathrm{I})$ \\
\hline Occupational therapist & $\mathrm{o}(\mathrm{o})$ & $0(0)$ & $6(6)$ & $\mathrm{I}(\mathrm{I})$ \\
\hline Housing officer & $\mathrm{o}(\mathrm{o})$ & $0(\mathrm{o})$ & $\mathrm{o}(\mathrm{o})$ & I $(\mathrm{I})$ \\
\hline
\end{tabular}

Notes: Figures are number (\%) of authorities exhibiting each association. Data were available for I07 local authorities. Sample sizes (minimum, maximum): medical consultants (IOI, IO2), general practitioners $(96,99)$, nurses (99, I04), social workers/care managers (I04, I06), occupational therapists (I03, I05), housing officers (99, I00).

These responses provided evidence about which professionals worked predominantly alone or together with others on a comprehensive assessment in the different sectors. Table 2 presents the cross-tabulations of professional group by the number of professionals involved in comprehensive assessments in the authorities. The figures are presented for each sector, and a number of interesting findings emerge. If we define multi-disciplinarity as three or more professionals involved in an assessment, it is notable that it occurred in only one sector, placements in care-home-with-nursing. More generally, the analysis reveals that medical practitioners (either consultants or general practitioners) were 
T A B L E 3. Summary of who assessed with whom and in which setting

\begin{tabular}{ll}
\hline Professionals & \multicolumn{1}{c}{ Roles } \\
\hline Social workers & $\begin{array}{l}\text { Mainly involved in three of the four considered settings (domiciliary } \\
\text { care, care homes and care-homes-with-nursing). Often assessed alone } \\
\text { except for care-homes-with-nursing, for which they most frequently } \\
\text { assessed with a nurse. } \\
\text { Usually assessed as single professionals for intermediate care and with } \\
\text { social workers for care-homes-with-nursing. Little involved in } \\
\text { assessments for other settings. } \\
\text { Generally not involved except for care-homes-with-nursing. }\end{array}$ \\
$\begin{array}{l}\text { Medical consultants } \\
\text { General practitioners, } \\
\text { and housing officers }\end{array}$ & Largely not involved in any setting. \\
\hline
\end{tabular}

rarely involved in assessments for other care arrangements. For intermediate care, where the responsibility for the assessment was vested in a single professional, this was just as likely to be a social worker/care manager as a nurse. This contrasts with placements in the care-home sector where, if undertaken by a single professional, he or she was most likely a social worker/care manager. These within-sector associations tentatively indicated the existence of some grouping of the local authorities in terms of the level of multi-disciplinary working. Where particular professionals were involved, one could discern whether they worked with other professionals or largely on their own in a particular sector. A summary of the most pertinent findings is provided in Table 3, which synthesises the principal differences in roles for three professions and for a residual group of three professions that were rarely involved.

\section{Evidence of systematic multi-disciplinarity}

Applying the Cramer's $V$ threshold to identify statistically-significant associations, five distinct arrangements emerged from the analysis (see Table 4). They point to groups of authorities that were organising comprehensive assessments in a similar way, involving similar numbers of professionals across sectors. From this, a typology of the multi-disciplinary arrangements across local authorities in England was produced. Table 4 presents the seven $(A-G)$ most prevalent arrangements. They represent different ways of working that varied in terms of the numbers and types of staff undertaking assessments in particular sectors. The seven categories accounted for almost two-thirds of the local authorities for which a full data set was available (68 out of $107,64 \%$ ). The predominant arrangement was assessment by a single professional. Four of the categories (A, B, $\mathrm{D}$ and $\mathrm{E}$ ) described three or more different types of arrangements. 
T A в L E 4. Arrangements for multidisciplinary assessments, England, 2005-06

\begin{tabular}{|c|c|c|c|c|c|c|}
\hline \multirow[b]{2}{*}{$\begin{array}{l}\text { Local } \\
\text { authority } \\
\text { category }\end{array}$} & \multicolumn{5}{|c|}{ Assessment arrangement ${ }^{1}$} & \multirow[b]{2}{*}{$\begin{array}{c}\text { Number } \\
\text { of local } \\
\text { authorities }\end{array}$} \\
\hline & $\begin{array}{l}\text { Intermediate } \\
\text { care: single } \\
\text { professional }\end{array}$ & $\begin{array}{l}\text { Domiciliary } \\
\text { care: single } \\
\text { professional }\end{array}$ & $\begin{array}{l}\text { Care home: } \\
\text { single } \\
\text { professional }\end{array}$ & $\begin{array}{l}\text { Care-home- } \\
\text { with-nursing: } \\
\text { social } \\
\text { worker + nurse }\end{array}$ & $\begin{array}{l}\text { Care-home- } \\
\text { with-nursing: } 3-5 \\
\text { professionals }\end{array}$ & \\
\hline A & $\checkmark$ & $\checkmark$ & $\checkmark$ & $x$ & $x$ & II \\
\hline B & $\checkmark$ & $\checkmark$ & $\checkmark$ & $\checkmark$ & $x$ & 9 \\
\hline C & $\checkmark$ & $x$ & $x$ & $x$ & $\checkmark$ & 7 \\
\hline D & $\checkmark$ & $\times$ & $\checkmark$ & $x$ & $\checkmark$ & 6 \\
\hline $\mathrm{E}$ & $\checkmark$ & $x$ & $\checkmark$ & $\checkmark$ & $x$ & I6 \\
\hline $\mathrm{F}$ & $x$ & $\times$ & $x$ & $x$ & $\checkmark$ & 8 \\
\hline G & $\times$ & $\times$ & $x$ & $\times$ & $\times$ & I I \\
\hline Total $^{3}$ & & & & & & 68 \\
\hline
\end{tabular}

Notes: $\checkmark=$ present, $x=$ absent. I. Only statistically valid associations were used to identify the arrangement categories (Cramer's $V \geqslant 0.3$ ). 2. Only associations found in 5 per cent or more of authorities were included. 3. Data were available for Io7 local authorities, 68 have been categorised.

Moreover, it would appear that the most frequently cited arrangements were not multi-disciplinary. Category $G$ occurred in II authorities in which no systematic associations between professionals across particular sectors were apparent.

\section{Discussion}

This article set out to discover whether assessments for older people with complex needs were being administered systematically across England following a major policy initiative, the SAP. The focus of the analysis was to investigate whether the approaches involved a multi-disciplinary component. Before discussing the findings and their implications, however, it is necessary to provide further information about the data collected from the sample of managers with broad strategic service knowledge and responsibility for local implementation of the policy. Their responses were estimates and present a picture of implementation from their perspectives. In its original form, one question asked whether the nominated professionals were 'always', 'sometimes' or 'never' required in comprehensive assessments in the distinct settings. In order to elicit the degree to which there was a systematic approach to the involvement of particular professionals in particular settings, only those who stated that a member of staff was 'always' required were included in the analysis. This, it can be argued, gives the estimates more weight, because if respondents were not sure they were more likely to have responded 'sometimes' than 'always'. 
This raised the possibility that our figures are under-estimates. However, the quantitative data for around three-quarters of English local authorities has enabled us to describe the combinations of assessors and the extent of multi-disciplinarity. The study could not and was not designed to address attitudinal and behavioural questions about inter-professional working and its facilitators and barriers.

As described in the introduction, the four settings used in the research reflected those outlined in the SAP guidance; they denote the different circumstances in which individuals with complex needs are likely to require a range of professional expertise in assessments. In the terminology of the SAP, this level of need should trigger a multidisciplinary comprehensive assessment. The findings suggest, however, that approximately two years after the formal introduction of the SAP in England, this by and large had not taken place, but rather that assessments for older people with complex needs were most often undertaken by single professionals. The question arises as to whether such assessments can include a consideration of all the domains required for a full comprehensive assessment (Kane and Kane 2000). In summary, the findings show that, in three of the four considered settings, an assessment by a single professional was most common. For only one setting, care-homeswith-nursing, were two or more professionals from different disciplines always involved.

The second finding relates to the nature of professional multidisciplinarity, which was rarely found to involve more than two professionals. A third finding relates to whether any logic could be discerned in the patterns of assessment practice across the settings and the country, regarding both which professions were most likely to work with each other and which most likely to be have the 'lead' or co-ordinating roles. In this respect intermediate care was distinctive, for the co-ordinating role was most frequently a social worker or care manager, and a community nurse was as likely as a social worker to either assess alone or to co-ordinate the assessment by requesting the involvement of a second professional. Lymbery (2005) commented on the neglect of social work input into intermediate care. Our findings suggest that social workers' role had expanded by $2005^{-0} 6$ but had not dominated the setting as had other professionals in other settings. Indeed, intermediate care was distinguished by more varied arrangements, with no one professional predominating. Intermediate care is a relatively new setting (or service) in the care of older people with very complex needs and, although research has identified a number of specific approaches in this area, there remains little knowledge as to the mix of professionals involved (Beech 2005). This is particularly the case regarding assessments for intermediate care, as opposed to the delivery 
of such care. The findings here provide useful information regarding practice in this emerging setting but clearly more research is needed.

As noted in the introduction, despite the rhetoric and the strong 'expert consensus' that multi-disciplinary teams provide the most effective care for older people with complex needs through their capacity to identify unmet needs and provide appropriate responses (Department of Health I997; Lingard and Milne 2004; Social Services Inspectorate 2003), two years and more after the introduction of the SAP in England, such teams were not the norm ( $c f$. Tucker et al. 2007). The findings reported here do not differentiate between multi-disciplinary assessments which took place within or between teams, but given the rarity of such teams beyond oldage mental health services, they are more likely to be undertaken between teams. The evidence therefore supports the call for the more widespread formation of multi-disciplinary teams, where they may be most likely to follow best assessment practice (Department of Health 2002). The integration of both agencies and professionals working with older people with health and social care needs remains high on the government's agenda in England, and the ambition remains to create joint health and social care managed teams or networks to support those with the most complex needs (Cm 6737 2006).

Finally, the findings suggest that a systematic approach to comprehensive assessments involving a multi-disciplinary component across the country was largely absent. A systematic approach to assessment suggests the establishment of mandatory procedures rather than 'custom and practice' arrangements, which are likely to exhibit greater variation between sites. The limited extent of systematic approaches to multidisciplinary assessment that has been shown suggests that such mandatory procedures have not been fully implemented or have not 'worked through' to practice on the ground. One of the key rationales for the introduction of the SAP was to promote a more standardised approach to assessment practice across England. A possible means of achieving this is the implementation of guidelines and protocols between professional groups and agencies regarding triggers for the involvement of specialist clinicians and other practitioners. Such a system would ensure that professionals clearly understand their specific roles and responsibilities as well as offering greater clarity to the older people that are being assessed. The guidance which accompanied the introduction of the SAP sought a level of flexibility in local implementation, however, which may have undermined the process of standardisation. This study suggests that more than one professional was only systematically involved in a comprehensive assessment where a care home provided a nursing element. Interestingly, it is only in relation to this setting that the guidance offered a degree of 
prescription, as the quotation in the introduction notes. In some ways it is surprising that development of the SAP appears least in the area of comprehensive assessment where the evidence base appears greatest for its potential impact (Challis et al. 1995, 2004). The outcomes of the pressure between local implementation and central guidance clearly varied across the service settings.

The process by which national policies are implemented locally is complex (Hill and Hupe 2002; Pressman and Wildavsky i973; Sabatier I986; Watt, Sword and Krueger 2005; Wilson 1992). Pressman and Wildavsky (I973) commented that it is remarkable that any policy initiative achieves a degree of effective implementation given the multifarious factors that can disrupt it. The level of prescription from the centre is one factor that can affect implementation, though not in a single direction. There are different schools of thought regarding the degree of local autonomy that should be encouraged if a national policy is to be both implemented and sustained in a manner which fits the local environment, but which does not result in an untenable level of 'policy drift' or modification (Charters and Pellegrin I973; McIntosh I985). There are those who argue that too much prescription will lead to a 'lack of ownership' by local managers and practitioners and consequently policy failure (Stocking I985). Others comment that mandatory prescription offers local providers clarity over which parts of a policy to prioritise (Barrett and Fudge i98I; Sabatier and Mazmanian 1979). Added to this complex picture is professional discretion at the local level (Lipsky 1980), which makes any national policy contingent on the attitudes and behaviour of front-line staff for its success.

There are lessons from recent history as to the difficulties in implementation of a national policy, particularly regarding comprehensive assessment, when localities are expected to follow guidance from the centre. An analogous policy to the SAP in the care of older people was that of the implementation of care management as promoted by the community-care reforms of the early I99os in England. In that policy, linkages between different assessments made by social workers or care managers and other professionals were envisaged and were clearly specified in the policy guidance (Department of Health 1990). This also advocated the assessment of older people's circumstances 'in the round' and, for it to become a reality, pointed to the need for all professionals and agencies, including general medical practitioners, primary health-care staff and social housing managers to collaborate in the assessment process (Department of Health I990: paras I.7-I.I3 and 3.9). Similarly, a subsequent central government directive required agreement on the basis of assessment systems as one of the key tasks in implementing these reforms 
(Department of Health i992). It has been argued, however, that the 'lead agency' status given to local government social services departments for the conduct of needs assessments as part of the community-care reforms resulted in a lack of attention to the links between health- and social-care assessments (Marks 1994). Practice after these reforms was reported as variable with integration being hampered by professional assessments running alongside each other rather than being explicitly linked (House of Commons Health Select Committee I998; Weiner et al. 2002). Thus, despite strong guidance from central government, locally the policy was not fully implemented in the way intended.

The promotion of the SAP similarly attempted to promote an active, multi-disciplinary structure of professional assessments for older people. It may be that tensions between central and local government, particularly in England (Banwell 1959; Rhodes I988), meant that the Department of Health's central prescription had to be tempered by sensitivity to local authorities' control over the way procedures on assessment were implemented. This may have resulted in the policy being rolled out differently in different areas, as some commentators predicted (Glasby 2004). In framing the SAP to address the related difficulties identified before implementation, it appears that central government has therefore sought to balance prescription with support for local authorities' own local efforts. It may be, as some authors commented (McNally, Cornes and Clough 2003), that this balance needs to be adjusted towards more central prescription as local areas have struggled with the implementation of the policy, particularly in deciding who should take on the co-ordinating role of bringing separate professional assessments together. Alternatively, approaches might be adopted which relied to a greater extent upon the development of trust and collaboration as mechanisms to support the effective roll-out of policy (Martin and Webb 2009; Webb I99I).

Writing I 5 years before the introduction of the SAP in England in 1989, Williams commented on the need for legislation to be used to help with the incorporation of multi-disciplinary geriatric assessment into the health and social care system. Williams argued that the complexities of some older people's mental and physical vulnerabilities made comprehensive multi-disciplinary assessment imperative:

To do this sensibly, information must be shared between the various professionals involved ... the whole concept of multi-disciplinary geriatric assessment will be successfully implemented only if it is integrated into, or has close liaison with, the rest of the health [and social care] system. (Williams I989: 150-4)

He noted that to realise this end, financial barriers between agencies and approaches that impeded the joint education of relevant professional 
groups would need to be addressed. This viewpoint is important for the insight it provides in framing the recent drive to improve the assessment process for older people throughout England. The SAP may be seen as a policy that can structure assessment, make it more effective, enable care planning and promote person-centred and more comprehensive care. Williams's comments, written before the recent changes, are still particularly apposite to the continuing project for improving assessment practice for older people with multiple and complex needs. Many of the issues that had been raised, principally the role of information sharing and the need for improved liaison between professionals, were explicitly addressed in the SAP (Department of Health 2002). The present findings suggest that the envisaged patterns of multi-disciplinary assessment for older people with more complex needs were not fully established in the early years, and the hoped for 'integration of multi-disciplinary assessment into the system' still had some way to go. The barriers to this, as identified by Williams (I989), remain some of the most pressing issues to consider in improving assessment for older people.

\section{Acknowledgements}

This work was undertaken by the Personal Social Services Research Unit (PSSRU) and funded by the Department of Health for England. The views expressed are those of the authors and not necessarily those of the Department of Health. The authors are grateful to Dwayne Johnson, Roger Lightup, Dave McNally, Ian Philp and Keith Wilson for their assistance with the design of the research tool, to Irene Pedersen for her work in promoting an effective response rate to the survey and to Sue Martin who provided secretarial support and was responsible for data entry.

\section{References}

Abendstern, M., Hughes, J., Clarkson, P., Sutcliffe, C., Wilson, K. and Challis, D. 2010. 'We need to talk': communication between primary care trust and other health and social care agencies following the introduction of the Single Assessment Process for older people in England. Primary Health Care Research and Development, I I, I, 6I-7I.

Applegate, W. B., Miller, S. T., Graney, M., Elam, J., Burns, R. and Akins, D. r99o. A randomised controlled trial of a geriatric assessment unit in a community rehabilitation hospital. New England Journal of Medicine, 322, 22, 1207-I4.

Audit Commission 1997. The Coming of Age. Stationery Office, London.

Audit Commission 2002. Integrated Services for Older People: Building a Whole System Approach in England. Public Sector Briefing Document, Audit Commission, London.

Australia, Department of Community Services 1986. Nursing Homes and Hostels Review. Australian Government Publishing Service, Canberra. 
Australia, Department of Health and Ageing 2007. The Australian Community Care Needs Assessment (ACCNA): Synopsis of Field Test Report and Eligibility and Assessment Working Group Response. Australian Government Department of Health and Ageing, Canberra.

Banwell, H. i959. The new relations between central and local government. Public Administration, 37, 3, 20I-I2.

Barrett, S. and Fudge, C. I981. Examining the policy-action relationship. In Barrett, S. and Fudge, C. (eds), Policy and Action: Essays on the Implementation of Public Policy. Methuen, London, 3-32.

Beech, R. 2005. Evidence on the effectiveness of Intermediate Care. In Roe, B. and Beech, R. (eds), Intermediate and Continuing Care: Policy and Practice. Blackwell, Oxford, Io6-I8.

Beswick, A., Rees, K., Dieppe, P., Ayis, S., Gooberman-Hill, R., Harwood, J. and Ebrahim, S. 2008. Complex interventions to improve physical function and maintain independent living in elderly people: a systematic review and meta analysis. The Lancet, 37ז, 9614, 725-35.

Booth, T. A. I98I. Collaboration between the health and social services: Part I, a case study of joint care planning. Policy and Politics, 9, I, 23-49.

Bouman, A., Rossum, E., Ambergen, T., Kempen, G. and Knipschild, P. 2007. Effects of a home visiting program for older people with poor health status: a randomized, clinical trial in the Netherlands. Fournal of the American Geriatrics Society, 56, 3, 397-404.

Bouman, A., Rossum, E., Nelemans, P., Kempen, G. and Knipschild, P. 2008. Effects of intensive home visiting programs for older people with poor health status: a systematic review. BMC Health Services Research, 8, 74, I-II. Available online at http://www. biomedcentral.com/I472-6963/8/74 [Accessed 23 June 2009].

Byles, J. E. 2000. A thorough going over: evidence for health assessments for older persons. Australian and New Zealand Fournal of Public Health, 24, 2, II7-23.

Cameron, A. and Lart, R. 2003. Factors promoting and obstacles hindering joint working: a systematic review of the research evidence. Fournal of Integrated Care, I I , 2, 9-17.

Carpenter, I. 1998. Standardised assessment in the community. In Challis, D., Darton, R. and Stewart, K. (eds), Community Care, Secondary Health Care and Care Management. PSSRU, University of Kent and Ashgate, Aldershot, UK, 89-iı6.

Challis, D., Darton, R., Johnson, L., Stone, M. and Traske, K. I995. Care Management and Health Care of Older People. Ashgate, Aldershot, UK.

Challis, D., Weiner, K., Darton, R., Hughes, J. and Stewart, K. 200I. Emerging patterns of care management: arrangements for older people in England. Social Policy and Administration, 35, 6, 672-87.

Challis, D., von Abendorff, R., Brown, P., Chesterman, J. and Hughes, J. 2002. Care management, dementia care, and specialist mental health services: an evaluation. International Journal of Geriatric Psychiatry, I 7, 4, 31 5-25.

Challis, D., Clarkson, P., Williamson, J., Hughes, J., Venables, D., Burns, A. and Weinberg, A. 2004. The value of specialist clinical assessment of older people prior to entry to care homes. Age and Ageing, 33, I, 25-34.

Charters, W. and Pellegrin, R. I973. Barriers to the innovation process: four case studies of differentiated staffing. Educational Administration Quarterly, 9, I, 3-I4.

Chevannes, M. 2002. Social construction of the managerialism of needs assessment by health and social care professionals. Health and Social Care in the Community, ro, 3, i68-78.

Clifford, P. I. 1997. Structuring the Clinical Record: The FACE Assessment and Outcome System. Main report to the Department of Health, Centre for Outcomes, Research and Effectiveness, University College London, London.

Cm 4818-I 2000. The NHS Plan. A Plan for Investment, A Plan for Reform. Stationery Office, London. 
Cm 6737 2006. Our Health, Our Care, Our Say: A New Direction for Community Services. Stationery Office, London.

Cowpe, J. 2005. Intermediate care: policy and context. In Roe, B. and Beech, R. (eds), Intermediate and Continuing Care: Policy and Practice. Blackwell, Oxford, 3-18.

Department of Health 1990. Caring for People: Community Care in the Next Decade and Beyond. Stationery Office, London.

Department of Health 1992. Implementing Caring for People: Community Care Packages for Older People. EL (92) I3, CI (92) io, i I March. Department of Health, London.

Department of Health ig93a. Monitoring and Development: Assessment Special Study. Department of Health, London.

Department of Health I993 b. Inspection of Assessment and Care Management Arrangements in Social Services Departments. Interim Overview Report, Department of Health, London.

Department of Health 1996. Caring for People at Home: An Overview of the National Inspection of Social Services Department Arrangements for the Assessment and Delivery of Home Care Services. Department of Health, London.

Department of Health 1997. At Home with Dementia: Inspection of Services for Older People with Dementia in the Community. Department of Health, London.

Department of Health 2001 a. National Service Framework for Older People. Department of Health, London.

Department of Health 200 $b$. Intermediate Care. HSC200 /or : LAC (200I) I, Department of Health, London.

Department of Health 2002. Guidance on the Single Assessment Process for Older People. HSC 2002/o0r : LAG (2002) I, Department of Health, London.

Department of Health 2008. Health and Care Services for Older People: Overview Report on Research to Support the National Service Framework for Older People. Department of Health, London.

Ellis, G. and Langhorne, P. 2005. Comprehensive geriatric assessment for older hospital patients. British Medical Bulletin, 7 I, I, 45-59.

Everitt, B. I992. The Analysis of Contingency Tables. Chapman and Hall, London.

Gill, T. M., Baker, D. I., Gottschalk, M., Peduzzi, P. N., Allore, H. and Byers, A. 2002. A program to prevent functional decline in physically frail, elderly persons who live at home. New England Fournal of Medicine, 347, I4, I068-74.

Glasby, J. 2003. Hospital Discharge: Integrating Health and Social Care. Radcliffe Medical, Abingdon, UK.

Glasby, J. 2004. Social services and the single assessment process: early warning signs? Journal of Interprofessional Care, 18, 2, 129-39.

Gostick, C., Davies, B., Lawson, R. and Salter, C. I997. From Vision to Reality in Community Care: Changing Direction at the Local Level. Ashgate, Aldershot, UK.

Gray, A. and Hunter, D. I983. Priorities and resource allocation in the Scottish health service: some problems in planning and implementation. Policy and Politics, I I, 4 , $4 \mathrm{I} 7-37$.

Hardy, B., Leedham, I. and Wistow, G. 1996. Care management co-location in GP practices: effects upon assessment and care management arrangements for older people. In Bland, R. (ed.), Developing Services for Older People and Their Families. Research Highlights in Social Work 29, Jessica Kingsley, London, I6I-78.

Hill, M. and Hupe, P. 2002. Implementing Public Policy. Sage, London.

House of Commons Health Select Committee 1998. The Relationship Between Health and Social Services. First Report Volume I, Session 1998-99, Report and Proceedings of the Committee. HC 74-I, Stationery Office, London.

Howe, A. L. and Kung, F. 2003. Does assessment make a difference for people with dementia? The effectiveness of the aged care assessment teams in Australia. International Fournal of Geriatric Psychiatry, 18, 3, 205-10. 
Hudson, B., Lewis, H., Waddington, E. and Wistow, G. 1998. Pathways to Partnership: The Interface Between Social Care and Primary Health Care: National Mapping Exercise. Nuffield Institute for Health, Leeds, UK.

Hunter, D. and Wistow, G. 1987. Community Care in Britain: Variations on a Theme. King Edward's Hospital Fund for London, London.

Ikegami, N. 1997. Public long-term care insurance in Japan. Fournal of the American Medical Association, 278, I6, I310-4.

Jorg, F., Boeije, H. R., Huijsman, R., de Weert, G. H. and Schrijvers, A. J. P. 2002. Objectivity in needs assessment practice: admission to residential home. Health and Social Care in the Community, ro, 6, 445-56.

Kane, R. L. and Kane, R. A. 200o. Assessing Older Persons: Measures, Meaning and Practical Applications. Oxford University Press, New York.

Kendig, H., McVicar, G., Reynolds, A. and O'Brien, A. I992. Victorian Linkages Evaluation. Department of Health, Housing and Community Services, Canberra.

Lewis, J. 200I. Older people and the health-social care boundary in the UK: half a century of hidden policy conflict. Social Policy and Administration, 35, 4, 343-59.

Lingard, J. and Milne, A. 2004. Integrating Older People's Mental Health Services: Community Mental Health Teams for Older People, a Commentary and Resource Document. Department of Health, London.

Lipsky, M. I980. Street-level Bureaucracy: Dilemmas of the Individual in Public Services. Russell Sage Foundation, New York.

Lymbery, M. 2005. Social Work with Older People: Context, Policy and Practice. Sage, London.

Marks, L. I994. Seamless Care or Patchwork Quilt? Discharging Patients from Acute Hospital Care. King's Fund Institute, London.

Martin, S. and Webb, A. 2009. Citizen-centred public services: contestability without consumer-driven competition? Public Money and Management, 29, 2, I23-30.

McIntosh, J. I985. District nursing: a case of political marginality. In White, R. (ed.), Political Issues in Nursing: Past, Present and Future. Wiley, Chichester, UK, 45-66.

McNally, D., Cornes, M. and Clough, R. 2003. Implementing the Single Assessment Process: driving change or expecting the impossible? Fournal of Integrated Care, II , 2, I8-29.

Moriarty, J. and Webb, S. 200o. Part of Their Lives. Community Care for Older People with Dementia. Policy Press, Bristol, UK.

Naylor, M. D., Brooten, D., Campbell, R., Jacobsen, B., Mezey, M. D., Pauly, M. V. and Schwartz, J. S. I999. Comprehensive discharge planning and home follow-up of hospitalized elders: a randomized clinical trial. Fournal of the American Medical Association, 28I, 7, 6r ${ }^{-20 .}$

O'Reilly, K. and Rose, D. I997. Criterion validation of the interim revised social classification. In Rose, D. and O'Reilly, K. (eds), Constructing Classes: Towards a New Social Classification for the UK. Economic and Social Research Council and Office for National Statistics, Swindon, UK.

Otis, N. and Butler, A. (eds) 1997. Assessment of Older People: A Review of Recent International Literature. Lincoln Gerontology Centre, La Trobe University, Melbourne.

Ovretveit, J. 1993. Co-ordinating Community Care: Multidisciplinary Teams and Care Management. Open University Press, Buckingham, UK.

Petch, A., Cheetham, J., Fuller, R., Macdonald, C. and Myers, F. with Hallam, A. and Knapp, M. 1996. Delivering Community Care: Initial Implementation of Care Management in Scotland. Stationery Office, Edinburgh.

Phelan, E. A., Williams, B., Pennix, B., LoGerfo, J. P. and Leveille, S. G. 2004. Activities of daily living function and disability in older adults in a randomised trial of the Health Enhancement Program. Fournal of Gerontology: Medical Sciences, 59A, 8, $838-43$. 
Philp, I. 2000. Easy-Care: a systematic approach to the assessment of older people. Geriatric Medicine, 3o, 5, I5-9.

Pressman, J. and Wildavsky, A. 1973. Implementation: How Great Expectations in Washington are Dashed in Oakland: Why it's Amazing that Federal Programs Work at all, this Being a Saga of the Economic Development Administration as Told by Two Sympathetic Observers Who Seek to Build Morals on a Foundation of Ruined Hope. University of California Press, Berkeley, California.

Reilly, S., Challis, D., Burns, A. and Hughes, J. 2003. Does integration really make a difference? A comparison of old-age psychiatry services in England and Northern Ireland. International fournal of Geriatric Psychiatry, I 8, Io, 887-93.

Rhodes, R. A. W. I988. Beyond Westminster and Whitehall. Hyman, London.

Rummery, K. and Glendinning, C. 2000. Primary Care and Social Services: Developing New Partnerships for Older People. Radcliffe Medical, Oxford.

Sabatier, P. I986. What can we learn from implementation research? In Kaufmann, F., Majone, G. and Ostrom, V. (eds), Guidance, Control and Evaluation in the Public Sector. De Gruyter, Berlin, 313-25.

Sabatier, P. and Mazmanian, D. I979. The conditions of effective implementation: a guide to accomplishing policy objectives. Policy Analysis, 5, 4, 48I-504.

Seigel, S. and Castellan, N. I988. Nonparametric Statistics for the Behavioural Sciences. McGrawHill, London.

Sheard, D. and Cox, S. 1998. Teams, Multi-disciplinary and Interprofessional Working and Dementia. Dementia Services Development Centre, University of Stirling, Stirling, UK.

Social Services Inspectorate 1997. The Cornerstone of Care: An Inspection of Care Planning for Older People. Department of Health, London.

Social Services Inspectorate 2003. Improving Older People's Services: An Overview of Performance. Department of Health, London.

Steiner, A. 200I. Intermediate care: more than a 'nursing thing'. Age and Ageing, 3o, 6, $433^{-}-5$.

Stocking, B. I985. Initiative and Inertia: Care Studies in the NHS. Nuffield Provincial Hospitals Trust, London.

Stuck, A. and Kane, R. L. 2008. Whom do preventive home visits help? fournal of the American Geriatrics Society, 56, 3, 56I-3.

Stuck, A. E., Siu, A. L., Wieland, G. D., Adams, J. and Rubenstein, L. 1993. Comprehensive geriatric assessment: a meta-analysis of controlled trials. The Lancet, $\mathbf{3 4 2}$, 8878, I032-6.

Tucker, S., Baldwin, R., Hughes, J., Benbow, S., Barker, A., Burns, A. and Challis, D. 2007. Old age mental health services in England: implementing the National Service Framework for Older People. International Journal of Geriatric Psychiatry, 22, 3, 21 I-7.

Warren, M. I946. Care of the chronic aged sick. The Lancet, 247, 6406, 84I-3.

Watt, S., Sword, W. and Krueger, P. 2005. Implementation of a health care policy: an analysis of barriers and facilitators to practice change. BMC Health Services Research, 5, 53. Available online at www.biomedcentral.com/I472-6936/5/53 [Accessed I July 2007].

Webb, A. I99I. Coordination: a problem in public-sector management. Policy and Politics, I 9, 4, 229-4I.

Webb, A. and Hobdell, M. I978. Co-ordination between health and personal social services: a question of quality. In Carver, V. and Liddiard, P. (eds), An Ageing Population: A Reader and Sourcebook. Hodder and Stoughton and Open University Press, Sevenoaks, $\mathrm{UK}, 33^{6-48 .}$

Webb, A. and Wistow, G. 1986. Planning, Need and Scarcity: Essays on the Personal Social Services. Allen and Unwin, London.

Weiner, K., Stewart, K., Hughes, J., Challis, D. and Darton, R. 2002. Care management arrangements for older people in England: key areas of variation in a national study. Ageing \& Society, 22, 4, 419-39. 
Williams, E. I. I989. Caring for Elderly People in the Community. Stanley Thornes, Cheltenham, UK.

Williamson, J., Stokoe, I. M., Gray, S., Fisher, M. and Smith, A. I964. Old people at home: their unreported needs. The Lancet, 283, 7343, II 7 -20.

Wilson, D. 1992. A Strategy of Change: Concepts and Controversies in the Management of Change. Routledge, London.

Accepted I8 March 2010

Address for correspondence:

David Challis, Personal Social Services Research Unit,

Dover Street Building, University of Manchester,

Oxford Road, Manchester Mis 9PL, UK.

E-mail: D.J.Challis@manchester.ac.uk 